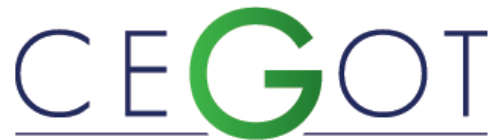

Centro de Estudos de Geografia e Ordenamento do Território
Penna, Lívea

Programa de Pós-graduação em Ambiente Construído Universidade Federal de Juiz de Fora

Rua José Lourenço Kelmer, s/n - São Pedro, 36036-900, Juiz de Fora - Minas Gerais, Brasil

livea.rocha@gmail.com

RIBEIRO, FILIPE

Programa de Pós-graduação em Ambiente Construído Universidade Federal de Juiz de Fora

36036-900, Juiz de Fora - Minas Gerais, Brasil

filribeiro@yahoo.com.br

ROCHA, CÉZAR

Programa de Pós-graduação em Ambiente Construído Universidade Federal de Juiz de Fora

36036-900, Juiz de Fora - Minas Gerais, Brasil

barra.rocha@gmail.com

FILHO, ANTÓNIO

Programa de Pós-graduação em Ambiente Construído Universidade Federal de Juiz de Fora

36036-900, Juiz de Fora - Minas Gerais, Brasil

arafilho2@globo.com

\title{
A utilização de reservatórios no amortecimento de vazões de cheia: apresentação e discussão de casos do sudeste brasileiro
}

The use of reservoirs in the dumping of flows: presentation and discussion of cases from the brazilian southeast

Referência: Penna, Lívea et al. (2019). A utilização de reservatórios no amortecimento de vazões de cheia: apresentação e discussão de casos do sudeste brasileiro. Revista de Geografia e Ordenamento do Território (GOT), n. ${ }^{\circ} 16$ (março). Centro de Estudos de Geografia e Ordenamento do Território, p. 275-295, dx.doi.org/10.17127/got/2019.16.012

\section{RESUMO}

O crescimento urbano desordenado impermeabilizando a superfície das bacias e ocupando as planícies de inundação têm como consequência as enchentes urbanas, cada vez mais constantes. Essas cheias produzem transtornos relacionados desde as perdas materiais até as perdas humanas. O objetivo deste artigo é apresentar um estudo comparativo de projetos em três grandes cidades do sudeste brasileiro para se enfatizar a importância do planejamento preventivo como solução mitigadora para impactos ambientais em larga escala. Verifica-se que a adoção de um modelo de drenagem falho, ainda utilizado em muitas cidades, coloca em risco a população urbana, sobretudo em áreas pouco infraestruturadas. Conclui-se sobre a necessidade da abordagem de novos conceitos de drenagem associados a projetos paisagísticos que promovam a qualificação do entorno.

Palavras-chave: Enchentes. Piscinões. Escoamento superficial. Águas pluviais. 


\section{ABSTRACT}

Urban sprawl, occupying flood plains, has resulted in urban floods, increasingly steady. These floods produce related disorders since material losses. The objective of this article is to present a comparative study of projects in three large cities of Southeastern Brazil to emphasize the importance of preventive planning as a mitigating solution for large scale environmental impacts. It is verified that the adoption of a flawed drainage model, still used in many cities, puts the urban population at risk, especially in poorly structured areas. It is concluded the is need to approach new drainage concepts associated with landscape projects that promote the qualification of the environment.

Keywords: Urban waters. Floods. Reservoirs. Surface runoff. Rainwater.

\section{Introdução}

Um dos maiores problemas de infraestrutura urbana no Brasil, ocasionado pelo intenso processo de urbanização, está relacionado à drenagem de águas pluviais. Com a expansão da malha urbana, amplia-se também o desmatamento e impermeabilização de superfícies, aumentando assim os picos de vazões, e consequentemente, podem ocorrer enchentes, quando as águas de determinado curso d'água atingem o limite de suas margens, ou inundações quando as águas transbordam além dessas margens (GOERL e KOBIYAMA, 2005). Os problemas das inundações urbanas podem ser agravados por uma série de fatores, como a grande impermeabilização dos solos; a ocupação inadequada das várzeas; a erosão e assoreamento; a retificação e canalização de rios e córregos; falhas nas leis de uso e ocupação de solos e contaminação da água, seja por depósito de resíduos sólidos urbanos, seja por efluentes domésticos ou industriais sem tratamento, ou por poluição difusa, que pode carrear grande quantidade de poluição orgânica e de metais, acarretando danos físicos, sociais e à saúde da população (TUCCI, 2008; CAMPANA; BERNARDES; SILVA, 2007 ).

Como medida paliativa para amortecimento dessas vazões de cheias, algumas cidades brasileiras adotaram reservatórios de detenção e retenção da água. Segundo Parkinson e Mark (2005) a diferença entre eles está em relação a presença de água no reservatório ao longo do ano, onde a bacia de detenção permanece seca fora dos eventos de cheias e a bacia de retenção apresenta uma lâmina d'água constante. De acordo com literatura consultada para desenvolvimento deste trabalho, a adoção dessas medidas sem 
planejamento pode gerar uma série de impactos negativos em termos ambientais, sociais, urbanos e paisagísticos. Seja pela falta de controle dos sistemas de esgoto e resíduos sólidos, pela realização de obras em caráter de urgência ou pela forma como os reservatórios são executados, o que compromete a preservação das várzeas e provoca degradação do entorno (BROCANELLI; ROSSINI; RODRIGUES, 2008; MOURA; PELLEGRINO; MARTINS, 2014).

Para isso, foram selecionados três reservatórios, o primeiro deles localizado na cidade do Rio de Janeiro, o segundo em São Paulo, e o terceiro em Uberaba, no estado de Minas Gerais. Sendo respectivamente, um reservatório de detenção subterrâneo, um de detenção aberto e um de retenção, para abarcar as diferentes tipologias.

Entendendo essa questão, esta pesquisa foi desenvolvida para compreender em uma amostra de três casos em cidades importantes do sudeste brasileiro, como se deu a inserção desses reservatórios na área urbana e seus impactos. Busca-se problematizar em que medida a adoção dessas estratégias de intervenção nos casos estudados revelam práticas que podem ser aperfeiçoadas com vistas a obter melhores resultados e desempenho.

\section{Das zonas alagadiças aos piscinões: breve contextualização histórica e o cenário brasileiro}

Segundo Silveira (2002), após constatar-se na Itália, durante o século XVIII, a relação entre zonas alagadiças e a mortalidade de pessoas e animais foi desencadeado, a partir da metade do século XIX, um processo de extinção de alagados, aterro de fossas receptoras de esgoto cloacal, a sua substituição por canalizações enterradas. Desta forma, deu-se origem ao conceito sanitarista-higienista. A partir deste conceito, adotado em vários países durante muitos anos e ainda presente em boa parte dos municípios brasileiros, a política de drenagem urbana consistia-se na evacuação de efluentes urbanos, de origem pluvial ou cloacal, o mais rápido possível para jusante. Esta abordagem tinha como finalidade minimizar a proliferação de doenças nos locais onde era instalada. 
Com o aumento da malha urbana, e com isso a consequente impermeabilização exagerada do solo, a canalização de rios e córregos e a incorporação das várzeas dos rios ao sistema viário acaba por ocorrer a aceleração dos escoamentos, aumentando os picos de vazão e ocasionando enchentes a jusante (CANHOLI 2005). Em países em desenvolvimento como o Brasil, um dos maiores problemas urbanos é a deficiência de coleta de esgoto, além de um baixo índice de tratamento daquele que é coletado (SILVEIRA, 2002).

No início do século XX ficou estabelecida pela Associação Brasileira de Normas Técnicas (ABNT, 1986), a separação da rede de drenagem de águas pluviais dos esgotos domésticos. Ainda assim é possível constatar que atualmente várias cidades brasileiras ou bairros de grandes cidades adotam sistemas unitários, ou seja, destinando efluentes de fossas sépticas para a rede pluvial. Além disso, existe uma porcentagem grande de contaminação das águas de drenagem pluvial e dos mananciais, resultantes de conexões clandestinas de esgoto na rede de drenagem. De acordo com dados levantados no ano de 2000 , mais de $80 \%$ do esgoto cloacal in natura distribuem-se por córregos, ruas e sistemas de drenagem (SOUSA FILHO, 2014).

Depois de constatada a ineficiência do conceito higienista como forma de saneamento, a partir da década de 1970 alguns países alteraram suas políticas de drenagem urbana, investindo em novas tecnologias de retenção de águas pluviais à montante. Este conceito também é encontrado entre os dispositivos do denominado Best Management Practices, BMPs, que se constitui de métodos de planejamento considerando toda a extensão da bacia. Detenções, retenções, pavimentos permeáveis, microrreservatórios, valas e trincheiras de infiltração são algumas das práticas aplicadas nessa forma de planejamento. As águas represadas pelos dispositivos da BMPs são liberadas posteriormente, de forma gradativa, diminuindo os picos de vazão, evitando as enchentes urbanas (BINGHAM; BOUCHER; BOUCHER, 1993).

De maneira geral, vemos que a forma como estes reservatórios são executados no Brasil somados ao contexto de falta do controle de sistemas de esgoto e resíduos, resultam em sua maioria, em comprometimento da preservação das várzeas e reservatórios a céu aberto. Os piscinões, em muitas das vezes, geram a degradação da paisagem onde são implantados (BROCANELLI; ROSSINI; RODRIGUES, 2008; MOURA; PELLEGRINO; MARTINS, 2014). 


\section{Reservação das águas em área urbana}

Os termos relacionados aos sistemas de drenagem ao longo dos anos foram bastante desenvolvidos em decorrência tanto das novas técnicas que surgiram principalmente nas últimas décadas, quanto da diversidade de áreas que passaram a tratar desse tema. Entre os termos utilizados nesse cenário, Fletcher et al (2015) destacaram: Low Impact Development (LID), sustainable urban drainage systems (SUDS), alternative techniques, water sensitive urban design e best management practices (BMPs), que foi o termo utilizado nesta pesquisa, por ser amplamente utilizado em pesquisas e trabalhos científicos e por abordar as práticas de reservação tratadas nesse artigo.

O conceito de reservação, segundo o BMPs, também conhecido como abordagem conservacionista, pode ser definido como o conjunto de medidas implementadas em uma bacia hidrográfica com o objetivo de atenuar os impactos da urbanização, considerando não só os aspectos relacionados à quantidade de água, mas também aqueles associados à qualidade da água que escoa sobre a bacia (AMEC, 2001). É preciso analisar criteriosamente as variáveis de cada local a se implantar uma ou mais BMPs, para que se possa definir qual a solução adequada do ponto de vista técnico, financeiro e social.

Os reservatórios atuam de forma a permitir a restituição à jusante de vazões compatíveis com um limite previamente fixado ou imposto pela capacidade de vazão de uma rede ou curso de água existente (BICHANÇA, 2006). As bacias de retenção contam com um dispositivo de descarga que não permite o escoamento da totalidade das vazões afluentes.

Desta forma, em situações de forte pluviosidade, proporcionam o armazenamento da água e a consequente subida de seu nível dentro da bacia. Com o tempo, a água é liberada lentamente, diminuindo o nível na bacia até que se atinja a situação de equilíbrio. Elas podem também proporcionar a captação de sedimentos, que depois de recolhidos, devem ser dispostos convenientemente em estações de tratamento de efluentes ou aterros sanitários. Em locais onde não há tecnologia adequada, tais poluentes são transportados pelas águas da lavagem do sistema viário e da ocupação do solo e lançados diretamente nos córregos. 
No Brasil, as formas mais usuais de reservatórios de detenção são os subterrâneos ou cobertos e os piscinões (reservatórios a céu aberto). Os reservatórios de detenção subterrâneos ou cobertos são, geralmente, empregados em zonas urbanas altamente povoadas, onde não existem áreas disponíveis para implantação de reservatório a céu aberto. Para os reservatórios subterrâneos é indispensável o recurso de sistemas de bombeamento para esvaziamento da bacia após o período de chuva. A cobertura destes reservatórios subterrâneos pode possibilitar a utilização do espaço para atividades públicas ou privadas (PINHEIRO, 2013).

Os reservatórios a céu aberto podem ser secos ou abrigar nível de água permanente. Quando secos, armazenam água apenas durante eventos de chuva e podem ser construídos com fundo impermeabilizado, quando há riscos de contaminação de águas subterrâneas pelas cargas elevadas de poluentes. Quando tais áreas são impermeabilizadas em concreto, podem desempenhar e incorporar outros tipos de funções, como por exemplo, a implantação de quadras de esportes e áreas de lazer.

A escolha do tipo de bacia de retenção, entre "seca" e de "nível de água permanente" depende de vários fatores, sociais e econômicos, como a aceitação da população, o tipo de integração paisagística que se pretende obter, o volume de armazenamento necessário para combater os problemas causados pelos picos de vazão, custos e outros (BICHANÇA, 2006).

Os reservatórios de detenção podem ser classificados também quanto à sua localização em relação ao curso d'água. Geralmente, a escolha da configuração e um reservatório, em série (online) ou em paralelo (off-line), é condicionada pela disponibilidade de área para construção da estrutura. Porém, ainda que estes reservatórios auxiliem na diminuição das ocorrências de inundações, a construção destas estruturas ainda hoje representa um retrocesso, pois do ponto de vista ambiental e social, não valorizam a paisagem integrandose ao entorno e não beneficiam ambientalmente o corpo d'água, sendo um local de acúmulo de resíduos e desvalorização da paisagem (SILVA, 2017). 


\section{Apresentação de casos no Sudeste brasileiro}

Foram considerados três contextos diferentes de implantação de reservatórios de detenção e retenção no Sudeste do Brasil. Localizado na cidade do Rio de Janeiro, o primeiro caso apresenta um reservatório de detenção construído em concreto sob uma área frequentemente afetada por enchentes em bairros da chamada "Grande Tijuca", especificamente na Praça da Bandeira. Ele faz parte de um sistema constituído por cinco piscinões e um desvio de rio ainda em execução.

O segundo caso está situado na zona leste da cidade de São Paulo e apresenta características bastante diferentes do primeiro, pois ao contrário do reservatório concretado e tamponado, o reservatório de detenção do Rincão permanece com o fundo impermeável e encontra-se aberto, caracterizado como um piscinão, sendo, portanto, também conhecido como piscinão do Rincão.

O terceiro caso encontra-se na cidade de Uberaba, Minas Gerais. Este último apresenta-se como um reservatório de retenção com fundo permeável e lâmina d'água, conhecido como piscinão do Parque das Acácias, e está localizado em um parque onde há atividades esportivas e de recreação.

\subsection{Reservatório de detenção Praça da bandeira - Rio de Janeiro / RJ}

A praça da Bandeira, situada na zona norte da cidade do Rio de Janeiro, foi construída sobre um antigo manguezal. O local, que sofre com chuvas intensas em época de cheias, formava um tradicional ponto de alagamento. Com a canalização e tamponamento de córregos e do mangue, o sistema hídrico foi desequilibrado, acarretando ainda mais as enchentes nesta área (SANTOS; MAMEDE, 2013).

Conforme ilustrado na Figura 1, o Programa de Controle de Enchentes da Grande Tijuca construiu cinco piscinões com capacidade total de $119.000 \mathrm{~m}^{3}$. O sistema é composto por três piscinões na Praça Niterói com capacidade para $58.000 \mathrm{~m}^{3}$, inaugurados em 25/10/2015; um Piscinão na Praça da Bandeira com capacidade para $18.000 \mathrm{~m}^{3}$, inaugurado em 29/12/2013 e um Piscinão na Praça Varnhagen com capacidade para $43.000 \mathrm{~m}^{3}$, inaugurado em 12/06/2016. Ainda completa esse sistema o desvio do Rio Joana que ainda 
encontra-se em construção, com $90 \%$ da obra concluída, passando em túnel perfurado sob os morros de São Cristóvão e da rua Fonseca Teles (PREFEITURA DO RIO DE JANEIRO, 2018).

O reservatório da Praça da Bandeira (R1) tem a função de captar as águas da drenagem local, diferente dos demais que são para conter as águas dos rios Trapicheiros (na Rua Heitor Beltrão - R2), que não foi construído, e Joana (na Praça Niterói - R3), Maracanã (na Praça Varnhagen - R4) e Jacó (no Alto Grajaú - R5). O desvio do Rio Joana criará um segundo deságue para as águas pluviais da Tijuca diretamente na Baía de Guanabara, evitando sobrecarga no Canal do Mangue (PREFEITURA DO RIO DE JANEIRO, 2018).

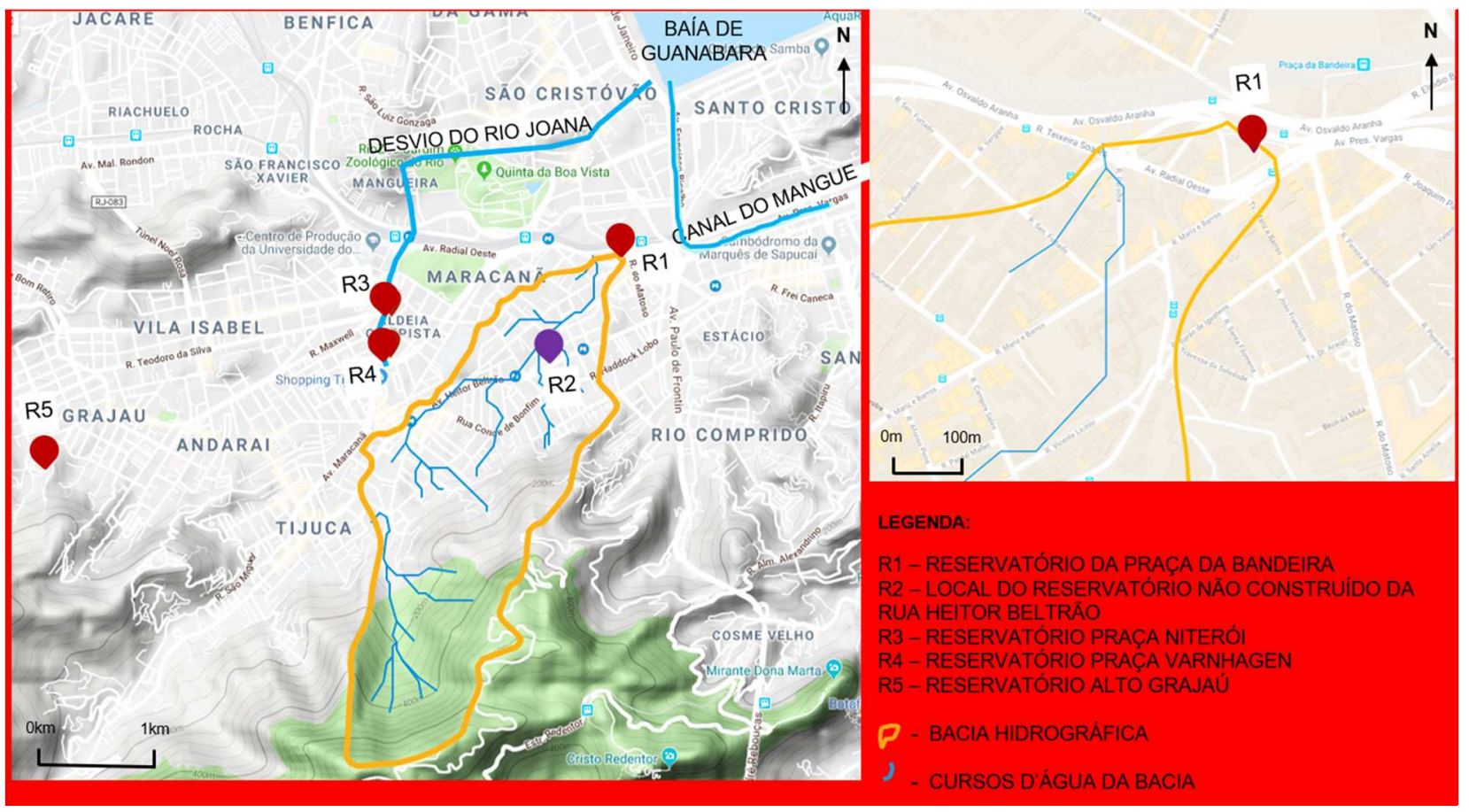

Figura 1 - Identificação da bacia e dos reservatórios mencionados no texto com destaque para a malha urbana da Praça da Bandeira.

Fonte: Elaborado pelos autores com base em Google my maps 2018 e em dados da Prefeitura do

Rio de Janeiro. Secretaria de obras do Rio de Janeiro - Rio águas. Disponível em:

<https://www.seaerj.org.br/pps/Apresentacao_SEAERJ_1_2013.pdf>. Acesso em: 31 out 2018.

Segundo Aluizio Canholi, que coordenou os estudos do Plano Diretor de Drenagem Urbana do Rio de Janeiro, o reservatório da praça da Bandeira foi projetado para receber somente a água excedente de seu entorno e suporta, no máximo em uma hora, uma chuva de 50 milímetros. Havia previsão de construção de um sexto reservatório, na rua Heitor Beltrão. Juntos, os piscinões já construídos têm a capacidade de armazenar 119 milhões de litros de água (MAGALHÃES, 2016). 
Segundo Marcelo Sepúlvida (2013), o reservatório da Praça da Bandeira possui 20 metros de profundidade útil e 35 metros de diâmetro. Para a sua execução lançaram mão do método construtivo de paredes diafragma, onde as laterais foram escavadas tendo como direção uma mureta guia e em seguida preenchidas com concreto. Além disso foi utilizada uma armadura de ferro de 30 metros de altura e 12 toneladas, formando ao todo 28 módulos de armadura.

Com base na literatura consultada, as opiniões técnicas em relação a Praça da Bandeira são divergentes. Segundo a Secretaria municipal de Saneamento e Recursos Hídricos, os reservatórios funcionaram conforme esperado em projeto. Porém, de acordo com o engenheiro Aluizio Canholi, citado por Magalhães (2016), o projeto original do reservatório da Praça da Bandeira deveria ter a capacidade de receber 100 milímetros de água pluvial em uma hora. No entanto, foi construído com a metade da capacidade projetada inicialmente em uma outra configuração. Segundo ele, foi cortado do projeto um importante reservatório localizado na rua Heitor Beltrão, que teria a função de receber grande parte da água excedente vinda da grande tijuca, evitando assim, o sobre acúmulo na Praça da Bandeira, que está em nível mais baixo. Entre essas e outras alterações, este sistema de reservatórios foram construídos ao total com $42,3 \%$ da capacidade projetada inicialmente.

Já para o engenheiro Adacto Ottoni, existem outras falhas no projeto, como a falta de investimento em um plano de saneamento para a Grande Tijuca, para tratar a questão do sistema de drenagem já existente, que acaba comprometido com o acúmulo de lixo na entrada dos reservatórios, promovendo a contaminação e provocando pontos de estrangulamento que acabam criando outros pontos de alagamento no entorno. Segundo ele, tal fato poderia ser combatido com uma série de medidas, como o reflorestamento de encostas contendo a água pluvial, um trabalho de educação ambiental com os moradores da região para evitar que o lixo seja descartado em lugares inapropriados e um trabalho de remoção das famílias em áreas de risco (MAGALHÃES, 2016).

Segundo Luciene Pimentel, professora do Departamento de Engenharia Sanitária e Meio Ambiente da Faculdade de Engenharia da Universidade Estadual do Rio de Janeiro, para que o desempenho do reservatório seja realmente efetivo é importante atentar-se a fase de manutenção dos reservatórios. Como foi identificado o problema do acúmulo de resíduos sólidos trazidos pelas águas da chuva, há a necessidade de limpeza e remoção constante 
destes resíduos de forma a permanecer disponível sua capacidade máxima em volume para receber as águas excedentes (ISSA, 2016).

Como ponto positivo foi identificado a reforma da Praça da Bandeira após as obras do reservatório, pois a mesma ganhou uma nova roupagem e transformou-se em um ponto de encontro dos moradores da região. Nela foram projetados, para a prática de atividades físicas, um rinque de patinação e academia ao ar livre, além de espaço para caminhada e convivência (PAES, 2015).

Entre os entraves identificados percebeu-se divergências de posicionamento em relação ao projeto por parte da prefeitura e dos especialistas, além do corte no orçamento para a execução do projeto, impossibilitando sua construção com a capacidade total projetada inicialmente. Ainda sobre este quesito, foi observada a necessidade de que todo o sistema fosse executado simultaneamente para garantir que exerça sua função sem prejudicar determinados pontos, por receberem a água que deveria ser amortecida em outro reservatório. Além disso, possíveis ações pontuais e/ou sistêmicas poderiam reduzir o volume do escoamento e melhorar a qualidade da água que chega aos reservatórios, como as soluções apontadas pelo especialista Adacto Ottoni, mencionado anteriormente. Deduzse que a não conclusão do reservatório na rua Heitor Beltrão (R2) com $70.000 \mathrm{~m}^{3}$ (quase 4 vezes o R1) poderá gerar novas enchentes, pois os outros reservatórios concluídos (R4 e R3) estão na sub-bacia ao lado. Houve melhoria, mas ainda existe risco de enchentes pelo R5 (Reservatório Alto Grajaú) e desvio do rio Joana ainda não concluídos na sub-bacia adjacente.

\subsection{Piscinão do Rincão - São Paulo / SP}

O piscinão do Rincão (Figura 2), inaugurado em 2002, está localizado na zona Leste de São Paulo, entre duas estações de metrô da linha vermelha, Penha e Vila Matilde. O terreno utilizado para a construção do reservatório é uma área lindeira de domínio público entre as linhas de metrô e trem, onde se encontra o córrego do Rincão. O córrego do Rincão passou por processo de retificação entre as décadas de 1970 e 1980, na época da construção da linha do metrô. A partir deste período, o terreno passou a receber apresentações circenses ocasionalmente. Devido à falta de espaços de esporte e lazer no entorno, a comunidade 
conseguiu concessão para o uso do espaço para estas atividades. Segundo Brocaneli (2008, p.14), ao longo do tempo a própria comunidade construiu campos e quadras esportivas, pista de bicicross, pista de cooper, playground, lanchonete com área coberta, instalações sanitárias e área coberta com mesas para jogos.

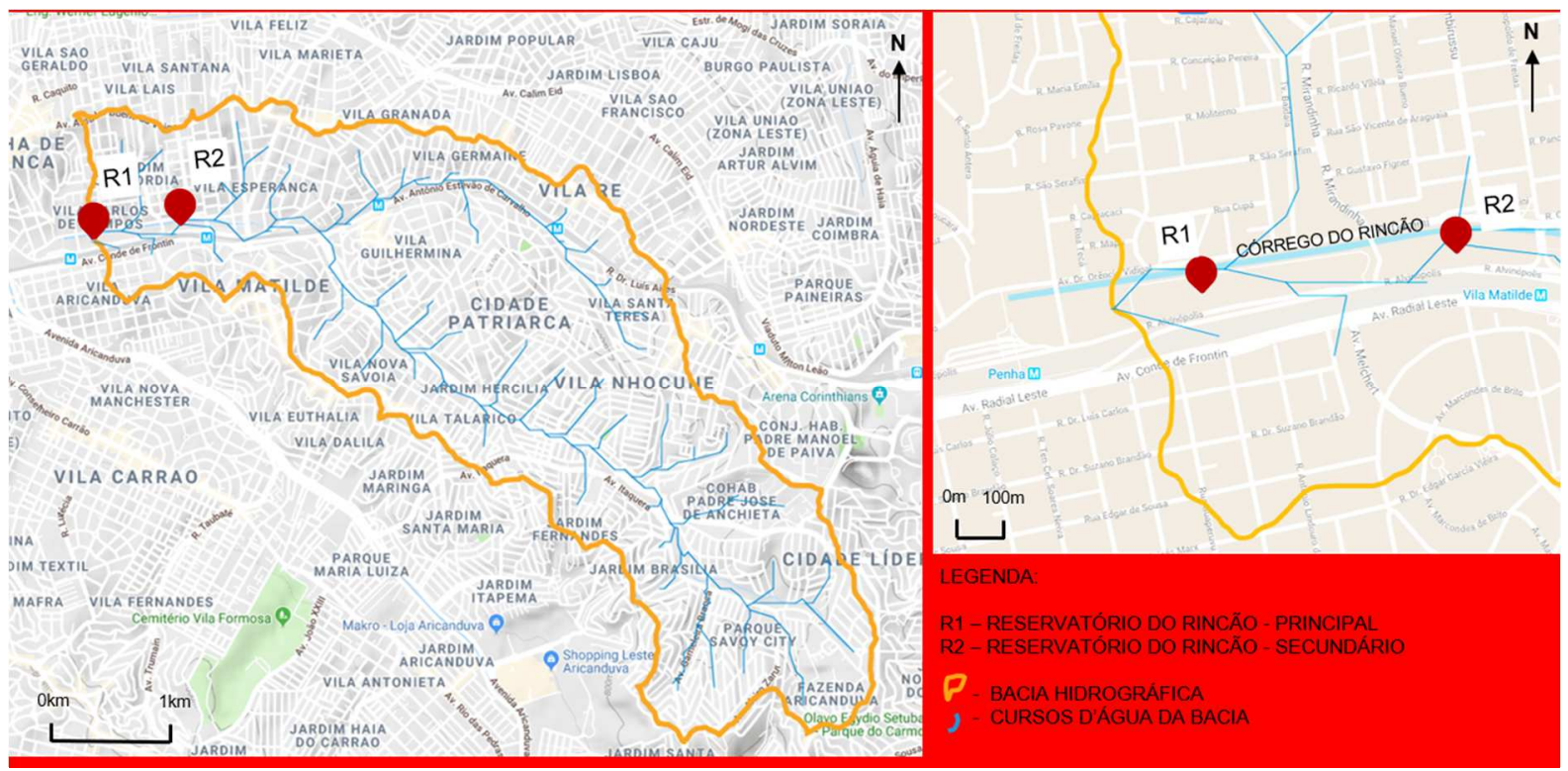

Figura 2 - Identificação da bacia e inserção do reservatório do Rincão na malha urbana.

Fonte: Elaborado pelos autores com base em Google my maps, 2018.

O Parque, com $100 \mathrm{mil} \mathrm{m}^{2}$, foi batizado de Parque do Rincão, e passou a receber cerca de 1.500 pessoas por dia (BROCANELI, ROSSINI, RODRIGUES, 2008).

Devido às enchentes na região, em 2002 a prefeitura autorizou a construção de reservatórios neste terreno para o recebimento da água excedente advindas das cheias do córrego do Rincão e do córrego Aricanduva, que ocupariam quase toda a área do parque. A comunidade se colocou contra o projeto durante meses, mas de nada adiantou e os piscinões foram construídos. Ainda segundo Brocaneli (2008, p.16), hoje a área apresenta um aspecto insalubre e mau cheiroso, mas apesar disto ainda recebe cerca de 1000 pessoas diariamente para atividades como caminhada e jogos de futebol dos times da comunidade em um campo improvisado (JORNAL DA TARDE SP, 2012).

Os reservatórios possuem, ao total, capacidade de 355 milhões de litros de água, sendo divididos entre o principal e o secundário (SANCHES; GONÇALVES, 2007). Segundo Raimundo (2007), a estrutura hidráulica do reservatório do Rincão foi construída de forma 
mista, ou seja, são combinadas diferentes estruturas de dissipação de energia, que neste caso consiste-se em um canal rápido seguido de uma bacia de dissipação curta.

De acordo com Sanches e Gonçalves (2007, p.695), “... esta construção foi responsável, em grande parte, pela degradação ambiental da única área verde de lazer do entorno". O piscinão do rincão diminuiu a qualidade de vida dos moradores da região, apesar de ter como objetivo inicial melhorar a qualidade de vida ao controlar as enchentes da região. A construção do piscinão acarretou uma série de outros problemas, como o acúmulo de lixo na área devido às poucas manutenções e o descaso da população, trazendo mal cheiro e mosquitos para a região. Há mais de uma década a prefeitura vem realizando projetos de caráter emergencial para controle das enchentes na capital paulista, às pressas e sem considerar uma série de fatores que posteriormente são atingidos pela instalação destes piscinões. Exemplo disso é a falta de atenção e cuidado com o entorno, que em sua maioria se tornam degradados, o que gera um grande impacto na sociedade e na economia local (BROCANELI, ROSSINI, RODRIGUES, 2008).

De acordo com a prefeitura de São Paulo (2013, p.24), o piscinão do Rincão recebe cerca de $51.224,64 \mathrm{~m}^{3}$ de resíduos por ano. Além disso, há a proliferação de vetores de doenças e problemas relacionados a falta de manutenção.

Entre os pontos positivos identificados está a eficiência do reservatório. Nogueira (2014) afirma que o reservatório do Rincão praticamente acabou com as enchentes da região. Outro ponto positivo identificado conforme consta no Relatório de Impacto Ambiental das obras de controle de inundações da bacia do alto Aricanduva (2013, p.33), o Parque do Rincão é o segundo localizado na bacia do Aricanduva que possui mais espécies de animais, totalizando treze.

O maior entrave para a construção do piscinão do rincão foi com a própria população local que se opôs fortemente ao projeto, que foi implantado justamente na área verde de lazer utilizada e construída pela comunidade. Apesar disso, de nada adiantou os protestos da população e o piscinão foi construído ocupando praticamente toda extensão do parque. Apesar de ainda utilizarem a área para caminhadas e para jogo de bola improvisado, houve uma grande diminuição do espaço disponível para estas atividades. 


\subsection{Piscinão do Parque das Acácias - Uberaba / MG}

O piscinão do Parque das Acácias se localiza na região central de Uberaba (Figura 3), no bairro Parque do Mirante, onde há histórico de frequentes inundações. O parque possui $140.700 \mathrm{~m}^{2}$ de área, sendo que o reservatório ocupa uma área aproximada de $70.000 \mathrm{~m}^{2}$ deste total (SILVA et al., 2013).

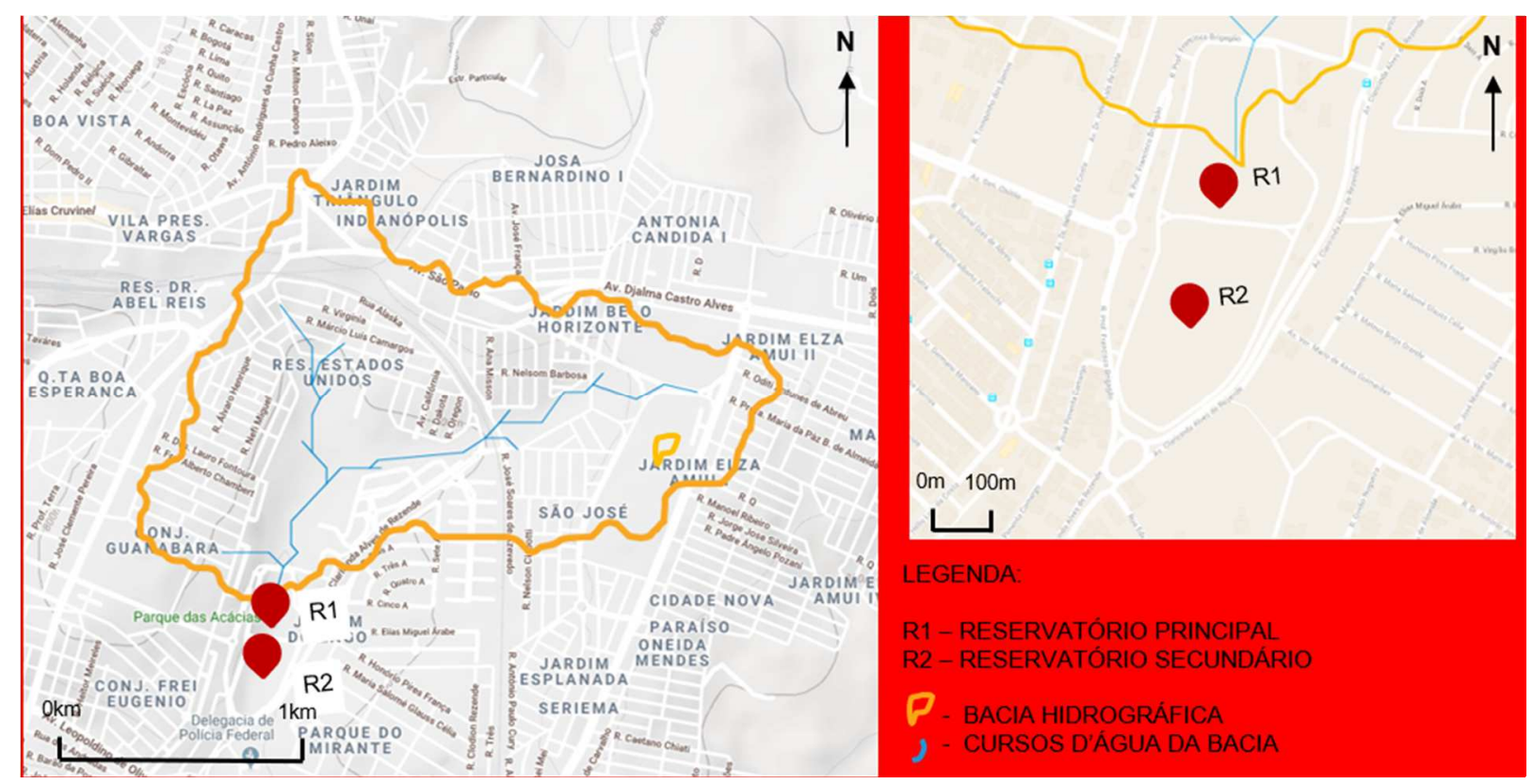

Figura 3 - Identificação da bacia e inserção do reservatório do Rincão na malha urbana. Fonte: Elaborado pelos autores com base em Google my maps, 2018.

A prefeitura de Uberaba, através do recebimento do Programa de Aceleração do Crescimento (PAC I e II) pelo governo federal, realizou o projeto Água viva, que consistiu em ampliar o sistema de microdrenagem e macrodrenagem existente na cidade. Em contrapartida a prefeitura realizou o piscinão do Parque das Acácias. Como a ocupação do entorno é relativamente recente, com o sistema de amortecimento de cheias na região, criaram-se inúmeros condomínios e bairros residenciais no entorno, o que aumentou o valor dos imóveis da região (PREFEITURA DE UBERABA CODAU, s.d.).

O sistema é composto de dois reservatórios: no primeiro, o reservatório principal, ocorre a retenção do volume excedente até que sua capacidade máxima seja atingida; quando isto ocorre há o escoamento para o segundo reservatório (através do chamado "sistema de ladrões"). Observa-se que a liberação de água é constante. No Parque, inaugurado em 2008 , encontram-se "pistas de caminhadas, quiosques, quadras poliesportivas, academia ao 
ar livre, pista de skate propício para o desenvolvimento de atividades físicas" (SILVA et al. 2013, p.1 e 5). O piscinão foi construído a partir de escavações em terreno natural, em taludes, até que atingisse as cotas de fundo e foi concretado nas laterais, permanecendo o solo permeável, com uma lâmina d'água constante de aproximadamente $1,50 \mathrm{~m}$ de profundidade, para que seja aproveitado para atividades de lazer e recreação.

Além das atividades de lazer disponíveis no dia-a-dia, o Parque recebe muitas visitas e ocasionalmente sedia eventos. Dentre todas as questões encontradas sobre o piscinão e o parque, não houve relatos de poluição e resíduos sólidos despejados diretamente no piscinão (UBERABA, 2013).

Apesar de ter melhorado significativamente as questões relacionadas às enchentes e alagamentos da região, o reservatório não foi o suficiente para solucionar completamente o problema. Além disso, Os usuários do parque reclamam da falta de iluminação, segurança e manutenção, e pedem mais arborização. Há, apenas, uma lanchonete na entrada do parque e falta manutenção (NAIARA, 2017).

\subsection{Análise dos dados e discussão}

Para melhor compreender a inserção dos reservatórios, foram levantadas características morfométricas das bacias, conforme apresentados na tabela 1.

\begin{tabular}{|l|c|c|c|}
\hline & Praça da Bandeira & Rincão & Parque das Acácias \\
\hline Área $\left(\mathrm{m}^{2}\right)$ & $5.808 .479,07$ & $15.831 .160,29$ & $2.566 .203,05$ \\
\hline Perímetro $(\mathrm{m})$ & $12.392,98$ & $23.776,56$ & $8.011,70$ \\
\hline Capacidade $\left(\mathrm{m}^{3}\right)$ & 18.000 & 355.000 & 210.000 \\
\hline Índice de Forma & 1,45 & 1,69 & 1,41 \\
\hline Cota Nascente (m) & 251 & 812,5 & 810 \\
\hline Cota Piscinão (m) & 3 & 736 & 773 \\
\hline $\begin{array}{l}\text { Comprimento do rio principal } \\
\text { (m) }\end{array}$ & $5.291,53$ & $8.376,93$ & $1.806,97$ \\
\hline Declividade Média (\%) & 4,69 & 0,91 & 2,05 \\
\hline
\end{tabular}

Tabela 1 - Considerações sobre as bacias de contribuição. Elaborado pelos autores. 
A Bacia de contribuição do Piscinão da Praça da Bandeira apresenta cerca de metade da sua área a montante coberta por mata (Figura 01). Entretanto a urbanização a jusante, combinada com a forma mais alongada da bacia $(\mathrm{IF}=1,45)$ e a declividade de $4,69 \%$ contribuem para a concentração de vazões rápidas no piscinão subterrâneo e impermeável, trazendo riscos à população do entorno.

A Bacia de contribuição do Piscinão do Rincão é a mais urbanizada conforme ilustra a Figura 2. A sua forma ainda mais alongada com relação às outras $(I F=1,69)$ e a menor declividade de $0,91 \%$ propiciam um deslocamento encaixado e mais lento das águas, distribuindo o risco ao longo da calha do rio principal. Mesmo sendo de fundo impermeável, o dispositivo consegue amortecer as vazões de cheia.

A Bacia de contribuição do Piscinão do Parque das Acácias ainda apresenta áreas não urbanizadas caracterizadas por solo exposto que permitem alguma infiltração (Figura 3). Sua forma é a menos alongada $(\mathrm{IF}=1,41)$, evitando a concentração das águas. Com uma declividade intermediária com relação às outras bacias, de 2,05\%, permite o deslocamento das águas para o dispositivo de retenção que tem fundo permeável, amortecendo as cheias.

Os casos apresentados mostram realidades distintas em vários aspectos com desdobramentos ainda não conclusivos.

O primeiro caso ressalta falhas técnicas, além da questão de redução de recursos. Observase que lançaram mão da construção de mais de um reservatório de detenção subterrâneo, completamente impermeável e o desvio do rio Joana diretamente para Baía de Guanabara ainda em implantação. Nota-se que além do custoso sistema implantado, ele depende da correta dimensão e manutenção de outros reservatórios para que consiga realmente solucionar o problema das enchentes conforme calculadas em projeto. Segundo Pinto e Martins (2010), é preciso fazer uma análise apurada das diferentes durações de precipitação e sua relação com toda a bacia ao adotar um reservatório de detenção, para que não se tenha resultados hidráulicos insatisfatórios.

No segundo caso, a implantação do piscinão foi feita em área de ocupação consolidada, onde havia uma área lindeira já apropriada pela população com atividades de lazer e esporte. Mesmo com a oposição dos moradores da região, o piscinão foi construído e hoje, após anos de seu funcionamento, são apresentados problemas relativos a manutenção do sistema de detenção, acúmulo de lixo na área e, consequentemente, o surgimento de insetos, podendo ocasionar a transmissão de doenças para a população. 
Ainda que o intuito inicial do projeto tenha sido melhorar a qualidade de vida dos moradores da região, amortecendo as enchentes recorrentes em períodos de cheias, o que se observa atualmente é uma baixa na qualidade de vida devido ao surgimento de outros problemas e a continuidade de casos de enchentes, pois a solução adotada contribuiu com a diminuição dos casos de enchentes na região, mas não o resolveu por completo.

No caso mineiro, observa-se que a ocupação do entorno ainda não era consolidada e havia uma grande área disponível. Este fato gera uma condição bastante diferente de implantação se comparado com o caso anterior, pois a partir da construção do Parque das Acácias, onde localiza-se o piscinão, consequentemente pela redução das enchentes, o valor imobiliário da área subiu.

A seguir, quadro-síntese comparativo dos três estudos de caso:

\begin{tabular}{|c|c|c|c|}
\hline \multicolumn{4}{|c|}{ Síntese comparativa } \\
\hline & $\begin{array}{c}\text { Reservatório Praça da } \\
\text { bandeira }\end{array}$ & Reservatório do Rincão & $\begin{array}{l}\text { Reservatório do Parque } \\
\text { das Acácias }\end{array}$ \\
\hline Localização & Rio de Janeiro / RJ & São Paulo / SP & Uberaba / MG \\
\hline Ano de inauguração & 2013 & 2002 & 2008 \\
\hline Local implatado & Praça & $\begin{array}{c}\text { Área lindeira de domínio } \\
\text { público } \\
\end{array}$ & Parque \\
\hline Tipo de reservatório & Detenção subterraneo & Detenção aberto & Retenção \\
\hline $\begin{array}{l}\text { Permeabilidade do } \\
\text { reservatório }\end{array}$ & Impermeável & Fundo Impermeável & Fundo permeável \\
\hline $\begin{array}{l}\text { Atividades no local } \\
\text { implantado }\end{array}$ & $\begin{array}{c}\text { Rinque de patinação, } \\
\text { academia ao ar livre, pista } \\
\text { de caminhada e áreas de } \\
\text { convivência. }\end{array}$ & $\begin{array}{l}\text { Pista de caminhada e } \\
\text { campo de futebol }\end{array}$ & $\begin{array}{l}\text { Recebe eventos; Possui } \\
\text { pistas de caminhadas, } \\
\text { quiosques, espaços } \\
\text { esportivos e áreas de } \\
\text { convivência. }\end{array}$ \\
\hline Benefícios identificados & $\begin{array}{c}\text { Apresenta infraestrutura } \\
\text { para prática de tividades } \\
\text { esportivas e espaços de } \\
\text { convivência. }\end{array}$ & $\begin{array}{l}\text { Praticamente amortece } \\
\text { toda vazão de cheia } \\
\text { necessária e apresenta } \\
\text { diversidade de } 13 \\
\text { espécies de animais. }\end{array}$ & $\begin{array}{l}\text { Amenizou o impacto das } \\
\text { enchentes na região, não } \\
\text { foram identificados relatos } \\
\text { de poluição e resíduos } \\
\text { sólidos, apresenta } \\
\text { atividades esportivas e de } \\
\text { lazer no entorno e } \\
\text { apresenta diversidade de } \\
\text { fauna e flora no entorno. }\end{array}$ \\
\hline Problemas identificados & $\begin{array}{l}\text { Acúmulo de resíduos } \\
\text { sólidos, pontos de } \\
\text { alagamento e } \\
\text { contaminação das águas } \\
\text { pluviais por poluição } \\
\text { difusa e contato com } \\
\text { esgoto. }\end{array}$ & $\begin{array}{l}\text { Mal cheiro, degradação } \\
\text { ambiental, redução do } \\
\text { espaço de lazer da } \\
\text { população local, acúmulo } \\
\text { de lixo, pouca } \\
\text { manutenção e foco de } \\
\text { proliferação de insetos. }\end{array}$ & $\begin{array}{l}\text { Apesar da diminuição de } \\
\text { ocorrência de enchentes, } \\
\text { não solucionou } \\
\text { completamente o problema } \\
\text { de enchentes na região. }\end{array}$ \\
\hline
\end{tabular}

Tabela 2 - Síntese comparativa dos reservatórios analisados. Elaborado pelos autores. 
Assim como foi observado nestes estudos, a realidade do sudeste brasileiro apresenta problemas e deficiências expressivas quanto ao uso dos reservatórios em área urbana, fato também identificado por Souza e Ottoni (2015), que apontou questões relevantes quanto a aspectos de análise de piscinões implantados no Brasil, os quais foram sintetizados nos tópicos abaixo:

a) Ausência de programas de coleta de esgotos e lançamento de grande carga de esgoto bruto diretamente nos cursos d'água, contribuindo com o assoreamento hídrico, a poluição fluvial e intensificando o risco de inundações.

b) Os reservatórios costumam não receber somente a água de chuva proveniente do escoamento superficial hídrico, mas também tendem a se tornar receptores da água de transbordo dos rios poluídos, além de carrear resíduos sólidos, contribuindo para o entupimento das grades de entrada do reservatório e possivelmente formando novas áreas de inundação.

c) Ausência de um programa expressivo de coleta seletiva e de reciclagem de lixo aliado a capacitação e educação ambiental da população.

d) Ausência de programas representativos que realizem a recuperação de replanntio de mata ciliar e vegetação de encostas.

e) Ausência de programas de recuperação de áreas de retensão natural destas águas.

Além de pouco investimento em projetos que alinhem soluções hidráulicas, ambientais, sociais, urbanas e paisagísticas, de forma integrada, possibilitando manter ou melhorar o equilíbrio entre os diferentes sistemas envolvidos e evitando a "resolução" de um problema, sem considerar os possíveis impactos gerados em toda a bacia. 


\section{Considerações finais}

Parece consensual afirmar que o processo de urbanização que é responsável pela alteração das características do solo afeta o escoamento das águas pluviais, e consequentemente o ciclo hidrológico da bacia. Tal fato ocasiona as enchentes e suas consequências negativas.

Uma das soluções aparentemente viáveis e eficazes para combater as enchentes é a instalações de bacias de reservação, pois retardam a vazão de pico e evitam o descarregamento da vazão excedente, ou parte dela, no sistema de drenagem a jusante no decorrer do evento. Porém, o caráter de urgência no qual é imposto a implementação destes dispositivos desconsidera uma série de fatores que deveriam ser analisados e planejados antes da implementação às pressas de uma ferramenta tratada como genérica, mas que vimos não ser. Um dos grandes problemas identificados após a implantação destes dispositivos está relacionado a falta ou pouca manutenção e operacionalização após executada.

Observamos que no Parque das Acácias, devido características peculiares locais e da forma como foi implantado o dispositivo de retenção, apresentou-se de forma geral, como uma boa solução. No entanto, vimos que em outros contextos, o resultado apresentou-se desfavorável interferindo negativamente no entorno e na comunidade, agregando problemas de ordem paisagística e/ou social.

É necessário, portanto, estudo aprofundado sobre a bacia, o solo, o ordenamento territorial, questões de risco ambientais e sociais para determinar a viabilidade de sua implantação, assim como um bom planejamento formado por uma equipe multidisciplinar para abarcar ao máximo possível as questões que envolvem um projeto do porte de um reservatório.

Ainda que se construam reservatórios de reservação, por meio de uma intervenção paisagística nestes sistemas, eles podem ser valorizados e otimizados, lançando mão de soluções que os transformem em locais mais atrativos e eficientes, expandindo a área de contato com o solo para aumentar a área de drenagem, permitindo a interação da população e acessos interessantes, que refutam a ideia de grandes vazios em meio a paisagem urbana. Além disso, deve-se sempre propor a utilização da vegetação como elemento de composição de uma paisagem multifuncional, servindo ao interesse público, 
não somente como paisagem decorativa, mas permitindo uma interação mais harmônica da paisagem com a população.

\section{Referências bibliográficas}

ABNT. Associação Brasileira de Normas Técnicas. NBR 9649. Projeto de redes coletoras de esgoto sanitário. Rio de Janeiro, 1986, 7 p.

BICHANÇA, M. F. Bacias de retenção em zonas urbanas como contributo para a resolução de situações extremas: cheias e secas. Dissertação de mestrado, Faculdade de Engenharia da Universidade do Porto, 2006. Acesso em: 18 set $2017 . \quad$ Disponibilidade: $\quad$ https://repositorioaberto.up.pt/bitstream/10216/12324/2/Texto\%20integral.pdf>.

BINGHAM, D.; BOUCHER, W.; BOUCHER, P., Handbook. Urban runoff pollution: prevention and control planning. U. Environmental Protection Agency. Office of research and development center for environmental research information Cincinnati, Ohio, 1993.

BROCANELI, P.; ROSSINI, M.; RODRIGUES, S. Os rios e a paisagem da cidade sustentável. 4 Fórum de pesquisa, FAU-Mackenzie, 2008. Acesso em: 20 set 2017. Disponibilidade: < https://pt.slideshare.net/mackenzista2/sustentabilidade-os-rios-e-a-paisagem-da-cidadesustentavel>.

CAMPANA, N. A.; BERNARDES, R. S.; SILVA, J. A. Controle qualitativo e quantitativo do escoamento pluvial urbanos com bacias de detenção. Revista Ambiente \& Água, 2007, vol. 2, n 3. Acesso em: 15 set 2017. Disponibilidade: < http://www.redalyc.org/html/928/92820310/ >. ISSN: 1980-993X.

CANHOLI, A. P. Drenagem urbana e controle de enchentes. 2a ed. São Paulo: Oficina de Textos, 2005.

FLETCHER, T.; SHUSTER, W.; HUNT, W. F.; ASHLEY, R.; BUTLER, D.; SCOTT, A.; TROWSDALE, S.; BARRAUD, S.SEMADENI-DAVIES, A.; BERTRAND-KRAJEWSKI, J. L.; STEEN MIKKELSEN, P.; RIVARD, G.; UHL, M.; DAGENAIS, D.; VIKLANDER, M. SUDS, LID, BMPS, WSUD and more - The evolution and application of terminology surrounding urban drainage. Urban water journal, 2015, vol. 12, p. 525-542. Acesso em: 29 out 2018. Disponibilidade: <https://www.tandfonline.com/doi/pdf/10.1080/1573062X.2014.916314>. ISSN: 1573-062X

GLOBOPLAY - Bom dia SP. Água jorra em piscinão na zona leste de São Paulo. 2014. Acesso em: 28 set. 2017. Disponibilidade: <https://globoplay.globo.com/v/3740806/>.

GOERL, R.F.; KOBIYAMA, M. Considerações sobre as Inundações no Brasil. XVI SIMPÓSIO BRASILEIRO DE RECURSOS HÍDRICOS, 2005. João Pessoa. Anais. Porto Alegre, ABRH, 2005. Acesso em: 25 out 2018. Disponibilidade: < http://www.labhidro.ufsc.br/Artigos/ABRH2005_inundacoes.pdf>.

ISSA, P. Chuvas de verão põem em prova o Programa de Controle de Enchentes da Grande Tijuca. 2016 Acesso em: 30 out 2017. Disponibilidade: < http://leduerj.com.br/ecosurbanos/detalhe.php?materia=2969>.

JORNAL DA TARDE - SP. Começa a obra do piscinão da penha, apesar dos protestos: a polícia teve trabalho para garantir o começo da obra. 2002. Revoltados, os moradores atiraram pedras e soltaram rojões em cima dos trabalhadores. Acesso em: 28 out. 2017. Disponibilidade: <http://notes.abcp.org.br:8080/producao/clipp/clipp.nsf/59dac160bc7df2ba03256aef00407549/c5ad3d69ddf 648e183256bd80043e993?OpenDocument>.

MAGALHÃES, L. E. Mudança em projeto de piscinão põe Praça da Bandeira em risco. 2016. Acesso em: 28 out. 2017. Disponibilidade: <https://oglobo.globo.com/rio/mudanca-em-projeto-de-piscinao-poe-praca-dabandeira-em-risco-18885138\#ixzz4thOWhBa9>

MOURA, N. C. B.; PELLEGRINO, P. R. M.; MARTINS, José R. S. Transição em infraestruturas urbanas de controle pluvial: uma estratégia paisagística de adaptação às mudanças climáticas. Paisagem e ambiente: ensaios, 2014, 
vol. 34, p. 107 - 128. Acesso em: 19 set 2017. Disponibilidade: <http://www.revistas.usp.br/paam/article/view/97125/96199>.

NOGUEIRA, M. R. Audiência pública bacia do aricanduva - licenciamento ambiental. Acesso em: 26 nov 2017. Disponibilidade:<http://www.prefeitura.sp.gov.br/cidade/secretarias/obras/obras_de_drenagem/bacias_hidr ograficas/index.php?p=183478>. 2014.

PAES, G. Praça da bandeira ganhará área de lazer no primeiro trimestre. 2015. Acesso em: 30 out. 2017. Disponibilidade: <http://aibnews.com.br/noticias/plantao-rio/2015/01/praca-da-bandeira-ganhara-area-delazer-no-primeiro-trimestre-2015.html>.

PARKINSON, J., MARK, O. Urban Stormwater Management in Developing Countries. Water Intelligence Online 5, Publishing London - Seattle, 2005. doi:10.2166/9781780402574.

PINHEIRO, L.. Projeto técnico: reservatórios de detenção. ASSOCIAÇÃO BRASILEIRA DE CIMENTO PORTALAND, Programa soluções para cidades. 2013. Acesso em: 02 de fev. de 2018 . Disponibilidade: <http://www.solucoesparacidades.com.br/wpcontent/uploads/2013/09/AF_Reservatorios\%20Deten_web.pd>

PINTO, L. L. C.; MARTINS, J. R. S. Proposta de metodologia para análise dos efeitos do emprego de reservatórios de detenção sob a ótica do conceito de impacto zero. 4 Congresso luso-brasileiro para o planejamento urbano, regional, integrado, sustentável. Portugal. 2010

PREFEITURA DE SÃO PAULO. Audiência pública bacia do aricanduva - licenciamento ambiental. 2014. Acesso em: $28 \quad$ out. $2017 . \quad$ Disponíbilidade: <http://www.prefeitura.sp.gov.br/cidade/secretarias/obras/obras_de_drenagem/bacias_hidrograficas/index. php?p=183478>.

PREFEITURA DE SÃO PAULO - Relatório de impacto ambiental das obras de controle de inundações da bacia do Alto Aricanduva. São Paulo - SP, 2013. Disponível em: < https://issuu.com/svmasp/docs/rima_vf>. 2013.

PREFEITURA DE UBERABA CODAU - Centro Operacional de Desenvolvimento e Saneamento de Uberaba. Projeto água viva relatório ambiental. Uberaba - MG, s.d. Acesso em: 28 out 2017. Disponibilidade: < http://www.uberaba.mg.gov.br/portal/acervo/agua_viva/arquivos/avaliacao_ambiental/Relatorio\%20Ambien tal\%202.pdf >. s.d.

RAIMUNDO, A. P. Estruturas hidráulicas utilizadas em reservatórios de controle de cheias. Dissertação de mestrado. Escola Politécnica da Universidade de São Paulo. São Paulo, 2007.

SANCHES, P. M.; GONÇALVES, J. C. Corredor verde Penha-Itaquera: estratégias de projeto e planejamento ambiental para áreas residuais na cidade de São Paulo. IV Encontro Nacional e II Encontro latino-amerciano sobre Edificações e comunidades Sustentáveis, 2007. Acesso em: 12 nov 2018. Disponibilidade:< http://www.elecs2013.ufpr.br/wpcontent/uploads/anais/2007/2007_artigo_060.pdf>.

SANTOS, L. B.; MAMEDE, B. Automação em drenagem pluvial e controle de enchentes: aproveitamento das águas nos grandes centros urbanos. Periódico eletrônico Fórum Ambiental da Alta Paulista, 2013, Vol. 9, n. 3.

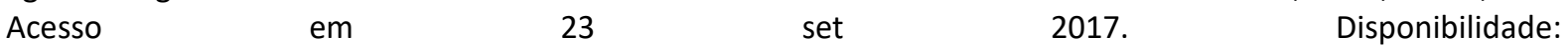
<http://www.amigosdanatureza.org.br/publicacoes/index.php/forum_ambiental/article/view/660/684> ISSN:1980-0827

SEPÚLVIDA, M; Preparando as olimpíadas: controle de inundações na Praça da Bandeira e Baixada de Jacarepaguá. Revista bi-anual - Ano XVIII - № 22 - Dezembro 2013, editada pela Sociedade dos Engenheiros e Arquitetos do Estado do Rio de Janeiro (SEAERJ). Acesso em: 30 out 2017. Disponíbilidade: <http://www.seaerj.org.br/pdf/RevistaSEAERJ.pdf>

SILVA, M. F.; SARDINHA, D. S.; MARTINS, P. D.; POLETO, C. Sistemas de amortecimento de cheias do Parque das Acácias na cidade de Uberaba (MG). IX Fórum Ambiental da Alta Paulista, 2013, v. 9, n. 2, p. 416-432.

SOUSA FILHO, J. F. Caracterização e avaliação do macro sistema urbano de distribuição de água de Natal RN. Dissertação de mestrado, Universidade Federal do Rio Grande do Norte, Natal, 2014.

SOUZA, T. M. K.; OTTONI, A. B. Análise Crítica Das Causas E Soluções Sustentáveis Para O Controle De Enchentes Urbanas: O Caso Prático Da Bacia Hidrográfica Da Praça Da Bandeira (Estudo De Caso). Revista Nacional de Gerenciamento de Cidades, 2015, v. 3, n. 17. Acesso em: 29 out 2018. Disponíbilidade: <file://C:/Users/1511\%20FOX/Downloads/1009-2030-1-SM.pdf>. ISSN: 2318-8472 
TUCCI, C. E. M. Águas urbanas. Estudos avançados (USP. Impresso), 2008, v. 22, p. 97-112. Acesso em: 22 set. 2017. Disponibilidade: < http://www.scielo.br/scielo.php?script=sci_arttext\&pid=S0103-40142008000200007> . ISSN: 1806-9592

UBERABA, Prefeitura Municipal. Entretenimento. Parque das Acácias. 2013. Acesso em: 22 set. 2017. Disponibilidade:<http://www.uberaba.mg.gov.br/portal/conteudo,634>. 